\title{
Are polygonal faults the keystone for better understanding the timing of fluid migration in sedimentary basins?
}

\author{
Aurélien Gay ${ }^{1, *}$ \\ ${ }^{1}$ Laboratoire Géosciences Montpellier (GM), CNRS UMR 5243, Place Eugène Bataillon, 34000 Montpellier, France
}

\begin{abstract}
The initial sediment lithification starts with complex interactions involving minerals, surface water, decomposing organic matter and living organisms. This is the eogenesis domain ( 0 to $2 \mathrm{~km}$ below the seafloor) in which the sediments are subject to physical, chemical and mechanical transformations defining the early fabric of rocks. This interval is intensively prospected for its energy/mining resources (hydrocarbons, metal deposits, geothermal energy). In most basins worldwide it is composed of very fine-grained sediments and it is supposed to play the role of a seal for fluids migration. However, it is affected by polygonal faulting due to a volume loss during burial by contraction of clay sediments with a high smectite content. This process is of high interest for fractured reservoirs and/or cover integrity but it is not well constrained giving an uncertainty as this interval can either promote the migration of deeper fluids and the mineralized fluids intensifies diagenesis in the fracture planes, rendering this interval all the more impermeable. The next challenge will be to define where, when and how does this polygonal fault interval occur and this can only be done by understanding the behavior of clay grains and fluids during early burial.
\end{abstract}

\section{Introduction}

On the Gjallar Ridge, the $800 \mathrm{~m}$ thick Middle OligoPliocene sequence is affected by small, closely-spaced intraformational faults, showing small throw values with a maximum of $30 \mathrm{msTWT}$ and spacing ranging from 200 to $1000 \mathrm{~m}$ (Fig. 1). Some of these faults almost reach the modern seabed, thus representing the top of a recently active polygonal fault system [1-5] (Fig. 2). Closely spaced polygonal faults form in fine-grained clay-rich sediments and they display a polygonal pattern in plane view [6-8]. Such fault systems have been recognised in many basins all over the world: in the North Sea $(6-7,9]$, in the China Sea [10-11], in the Australian Eromanga Basin [12], in the Lower Congo Basin [13], in the northern Danish Central Through [14] and in the Canadian Atlantic margin [15]. They are usually interpreted as layer-confined because they occur within sub-horizontal intervals generally associated with lithological variations of the host sediments. Distinct fault tiers are defined by their own fault frequency and spacing due to different mechanical properties of the intervals [6-7, 16-18]. However, as already shown by studies in the North Sea, polygonal faults do not abruptly end at a specific stratigraphical horizon $[6,16]$. Other mechanisms different from lithology variation have been referenced in the literature as responsible for polygonal fault initiation and propagation, such as diagenetic transformations [4-5] or reactivation by sediment loading $[2,13]$ for example. Four hypotheses are actually proposed to explain the formation of these polygonal faults: i) syneresis related to colloidal properties of such fine-grained sediments [8], ii) density inversions and associated hydrofracturing [19], iii) smectite-rich clays causing residual friction at low burial depth [20-21] and iv) grain dissolution in uncemented media inducing a decrease in horizontal stress that leads to shear failure and shear strain localization [22-23]. Polygonal faults are linked to fluid flow as they form pathways for upwardfluid migration from deeper levels [13, 21, 24]. However, the mineralized fluids intensifies diagenesis in the fracture planes, rendering this interval all the more impermeable [25]. Thus the kinematic model of polygonal fault growth in which the propagation of faults is discontinuous during basin infilling leads to a 4D interpretation of the whole fault system which will be one of the next challenge in basin modelling.

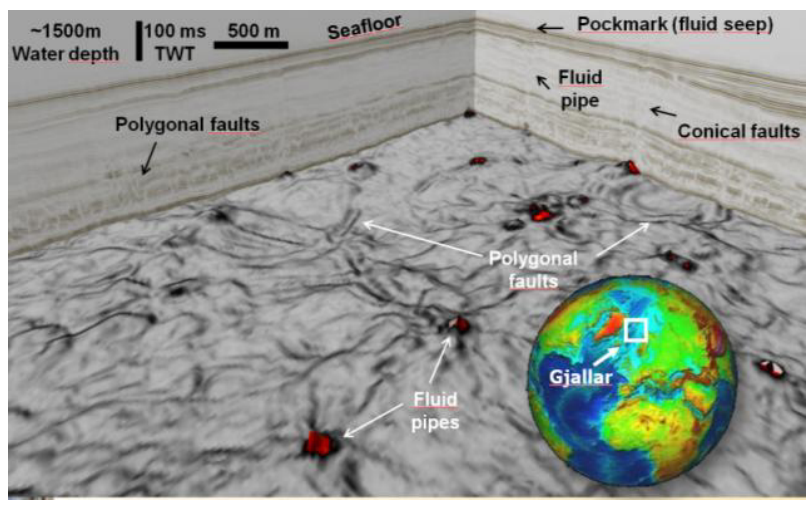

Fig. 1. The polygonal network in the Gjallar Basin (Norway) from 3D seismic data, showing the relation with conical faults and fluid pipes (Variance attribute).

\section{Architecture and initiation}

The first hypothesis for polygonal faults formation considers a finite bed length extension and the development of conjugate shear planes with extensional offsets due to the loss of pore fluids. This process leads to a thinned sequence, which is partly compacted [26].

\footnotetext{
Corresponding author: author@e-mail.org
} 
The second hypothesis considers that there is no change in the horizontal length and shear planes represent an apparent extension [26]. The consequences are that the complex polygonal fault systems in mudstone dominated sequences formed due to volumetric contraction during compactional dewatering $[2,13,26]$. This process is believed to occur in response to fluid expulsion during early compaction, leading to a bulk volume loss. The low permeability of fine-grained argillaceous sediments would impede the pore fluid expulsion during burial by an increase in pore fluid pressure in the sealed layer initiating failure.

Increased dewatering during burial implied more displacement along faults, which would continue to grow as long as the dewatering cell contracted volumetrically. This mechanism induces a component of tensile stress within the sediment mass resulting in the reduction of the horizontal effective stress and the Mohr circle can intersect the failure envelope in the shear domain leading to the propagation of non-vertical faults $[8,26]$. The progressive reduction in bed length through contraction is balanced by an incremental increase in the amount of displacement distributed along the faults.

On the seismic data, major polygonal faults exhibit breached relays or overlapped fault-segments. Their fault planes show a succession of throw maxima separated by horizontal throw minima located in the relay zones [25]. This pattern is interpreted in the brittle domain as a reactivation by dip-linkage of two individual sub-parallel fault segments [27-28] (Fig. 2).

However, recent studies have shown that the linkage zone is consistent with boundaries of mechanical units and the throw maxima correspond to the centre of units [25]. It suggests that the nucleation of polygonal faults occurs at the centre of a mechanical unit, when the threshold of compaction is reached allowing shear localisation on fault. Then faults grow in any direction, both upward and downward. They can connect to underlying pre-existing intervals of polygonal faults or reaching the seabed forming pockmarks and allowing fluid to escape into the water column.

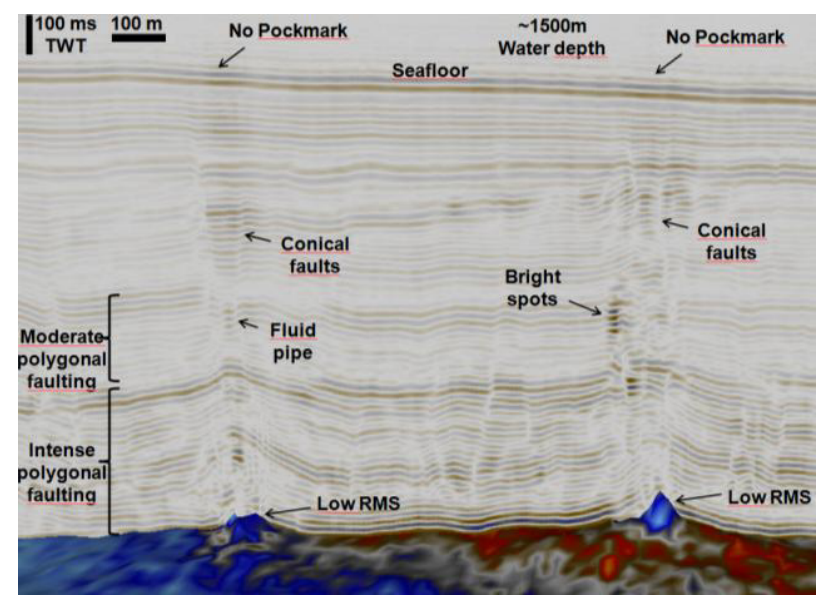

Fig. 2. 2D seismic profile showing anomalies, such as conical faults, fluid pipes, bright spots and pockmarks, due to the upward migration of fluids through the polygonal fault interval.

\section{Processes}

In most basin models, compaction and related phenomena are assumed to be due to mechanical effects in the first $0-2000 \mathrm{~m}$ in response to the progressive loading of sediments [29]. As sediment porosity decreases with compaction, so does the permeability, due to a set of processes involving particle re-orientation and fluid expulsion leading to the decrease of void spaces between particles [29-30]. Overpressure development in sedimentary basins is thus directly related to lithology, sedimentation rate, thermal expansion of fuids, transformation of clay minerals and hydrocarbon generation or bacterial methanogenesis [31]. Among these factors, grain size and sedimentation rates are of primary importance in controlling fuid pressure development in a basin.

Normal faulting related to burial and sediment loading is not a common process that has been proposed for rocks deformation, which is probably because soft sediments like clays have a specific behaviour. The main factor controlling the development of polygonal fault systems is the grain size [8]. However, the dominant orientation of faults as well as their bending in the slope direction suggests the interaction of gravity-driven shearing of the compacting interval. The appearance of polygonal fault system reaching the seafloor could thus be indicative of the present day strain state within the sedimentary column [32].

A radial stress tension related to the volumetric contraction of clay could allow to reduce the lithostatic mean stress, also increasing the differential stress, and then to reach shear failure along a Coulomb-type conventional envelope. However this process assumes (i) that the faulted material has a common frictional envelope, (ii) that the lithostatic stress state prior to faulting due to compaction was sub-critical, i.e. close to shear failure, and/or (iii) that the stress tension related to the volumetric change is large enough. In such a nonlithified and uncompacted clay sediment, the coefficient of Earth pressure at rest $(\mathrm{Ko})$ is generally large $(0.45-$ 0.8 ) implying a little differential stress due to the vertical loading [33-36]. This therefore suggests that if a radial horizontal tension is added due to volume contraction, it needs to be very large to increase the differential stress and get the failure envelope. However, as mentioned above, the behaviour of clays is actually quite far from the simplistic Coulomb type or Druker-Prager Model, and faulting comes frequently with non-isochoric shear, i.e. with compaction, as for example what happens in clay smears [37-38]. Yielding of clay materials have been described as following Cam-clay behaviour in $q-p$ diagram ( $\mathrm{q}$ is differential stress and $\mathrm{p}$ is mean stress) in which the yielding envelope has a cap, i.e. it is closed for relatively high mean stresses (Fig. 3a). This part of the material envelope has been described in plasticity theory as a behaviour allowing strain localisation [39-41] especially in soft materials as for example porous sandstones [42]. This model allows distributed pure compaction for high mean stress and localised pure shear at the critical state point (intersection of Coulomb type envelope with the cap). The interesting window of this 
cap envelope is the intermediate behaviour between these two end member points, along which localisation can start as shear compactional banding (i.e. clay smearing and subsequent compaction). This part of the envelope has a large probability to be crossed by a burial curve since it is below the Coulomb-type part of the envelope (see the location of the white star in Fig. 3b) and that strain hardening due to compaction, even moderate, must favour a non-linear stress path on the q$\mathrm{p}$ diagram. Therefore, the conjunction of (i) possible localisation along a cap side of the clay envelope, (ii) a linear Coulomb-like part of the envelope with low coefficient of friction and (iii) burial with horizontal contraction and work hardening (bold dashed line) give mechanical support for the initiation of shear localisation related to burial. This could be also favoured by perturbed local stresses at the tip or the vicinity of another fault.
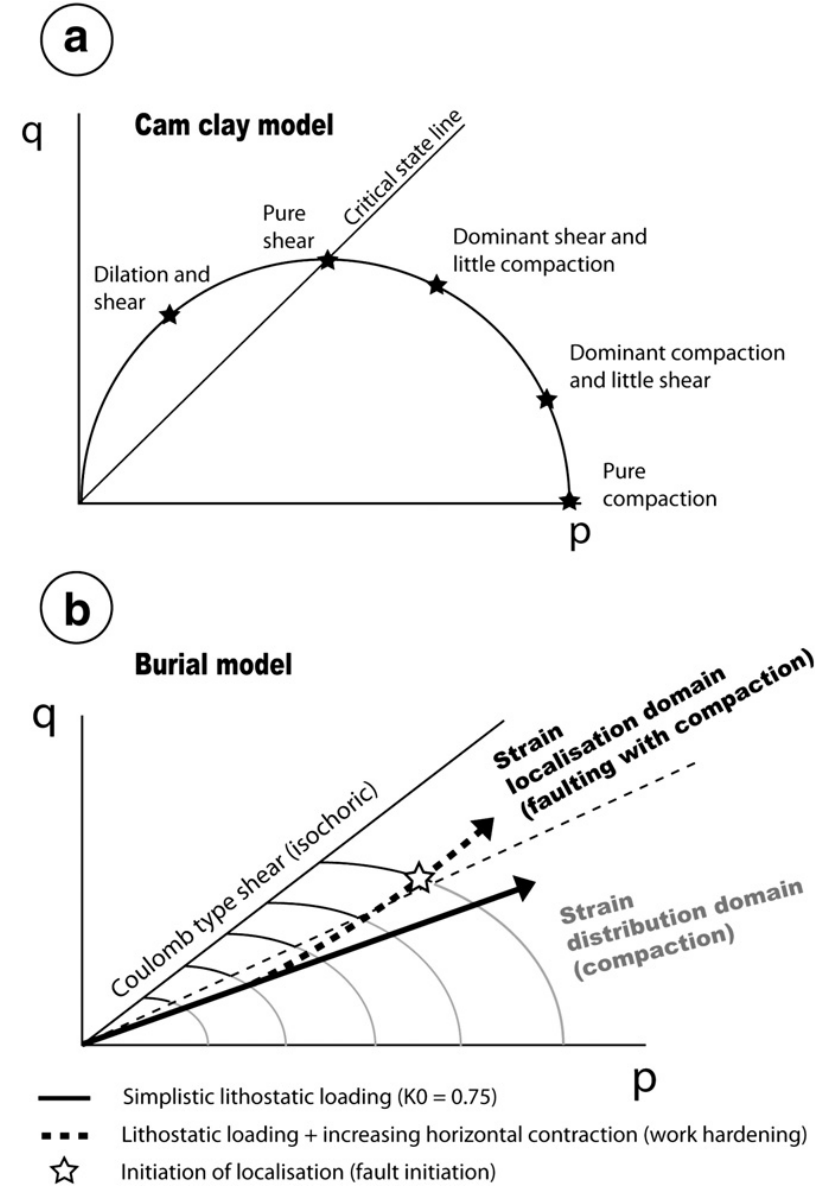

Fig. 3. (a) Diagram of a Cam-clay model (modified after Rudnicki, 2004) in which differential stress (q) versus mean stress (p) diagram shows a yielding envelope for clay materials with a cap, allowing behaviour of strain localisation. (b) Diagram of burial model in which yielding envelope is crossed by a burial curve corresponding to the addition of compaction and horizontal contraction of clay sediments leading to shearcompactional strain (white star).

The process of shear localisation on a cap part of the clay yielding envelope is consistent with the low dip angle of the polygonal faults observed $\left(50^{\circ}\right.$ to $\left.60^{\circ}\right)$, which is attempted for shear banding having little compaction and/or material having low friction coefficient. This does not preclude these shear compaction strains to evolve into "real" faults (isochoric shear) by strain hardening of the material as the result of the progressive compaction (bold dashed line reaching the Coulomb-type line, Fig. 3b). This mechanical concept suggests that progressive sediment loading acts as a centrepiece in the initiation and propagation of polygonal faults $[2,13,43]$. It also implies that, at great burial depths, the compaction through the process of volumetric contraction ends and the dissolutionprecipitation mechanisms become dominant $[13,44]$

\section{Conclusion}

3-D seismic data provide new insights on the margin history and improve the understanding of postdepositional processes that affect the sedimentary column. During eogenesis in mud-dominated sediments numerous polygonal faults are initiated. This process is of high interest for fractured reservoirs and/or cover integrity, even in the extraterrestrial exploration [45-46]. However, at present day, polygonal faults have never been sampled nor modelled giving an uncertainty in their ability for driving fluids from deeper levels [47]. The next challenge will be to define where, when and how does this polygonal fault interval occur and this can only be done by understanding the biphasic behaviour of clay grains and fluids during early burial.

\section{References}

1. J.P.V. Hansen, J.A. Cartwright, M. Huuse, O.R. Clausen, Bas. Res. 17 (2005)

2. A. Gay, C. Berndt, JGS of London 164 (2007)

3. R.J. Davies, M.T. Ireland, J.A. Cartwright, Bas. Res. 21 (2009)

4. R.C. Neagu, J.A. Cartwright, R.J. Davies, J. of Str. Geology 32 (2010)

5. M.T. Ireland, R.J. Davies, N.R. Goulty, D. Carruthers, Sedimentology 58 (2011)

6. J.A. Cartwright, Geology 22 (1994)

7. L. Lonergan, J.A. Cartwright, R. Jolly, J. of Str. Geology 20 (1998)

8. D.N. Dewhurst, J.A. Cartwright, L. Lonergan, Mar. and Petr. Geology 16 (1999)

9. J.A. Clausen, R.H. Gabrielsen, P.A. Reksnes, E. Nysaether, J. of Str. Geology 21(10) (1999)

10. C. He, C. Tang, D. Huang, S. Shi, Min. Sc. and Tech. 20 (2010)

11. Q. Sun, S. Wu, F. Lü, S. Yuan, J. of As. Earth Sciences 39 (2010)

12. J.A. Cartwright, L. Lonergan, Expl. Geophysics 28 (1997)

13. A. Gay, M. Lopez, P. Cochonat, G. Sermondadaz, Bas. Res. 16 (2004)

14. J.A. Clausen, J.A. Korstgård, J. of Str. Geology 15 (1993)

15. D.M. Hansen, J.W. Shimeld, M.A. Williamson, H. Lykke-Andersen, Mar. and Petr. Geology 21 (2004)

16. J.A. Cartwright, Mar. and Petr. Geology 11(5) (1994) 
17. R.V. Ackermann, R.W. Schlische, M.O. Withjack, J. of Str. Geology 23 (2001)

18. R. Soliva, A. Benedicto, J. of Str. Geology 27 (2005)

19. J. Watterson, J. Walsh, A. Nicol, P.A.R. Neil, P.G. Bretan, JGS of London 157 (2000)

20. N.R. Goulty, JGS of London 159 (2002)

21. N.R. Goulty, Petr. Geoscience 14 (2008)

22. H. Shin, J.C. Santamarina, J.A. Cartwright, Geology 36 (2008)

23. H. Shin, J.C. Santamarina, J.A. Cartwright, JGR 115(B7) (2010)

24. C. Berndt, S. Bunz, J. Mienert, Geol. Society of London Sp. Pub. 216 (2003)

25. D. Laurent, A. Gay, C. Baudon, C. Berndt, R. Soliva, S. Planke, R. Mourgues, S. Lacaze, F. Pauget, M. Mangue, M. Lopez, Mar. Geol. 332-334 (2012)

26. J.A. Cartwright, L. Lonergan, Bas. Res. 8 (1996)

27. C. Childs, A. Nicol, J. Walsh, J.J. Watterson, J. of Str. Geology 18 (1996)

28. C. Baudon, J.J. Cartwright, J. of Str. Geology 30 (2008)

29. G. Vasseur, I. Djeran-Maigre, D. Grundberger, G. Rousset, D. Tessier, B. Velde, Mar. and Petr. Geology 12 (1995)

30. A. Maltman, The Geological Deformation of Sediments (1994)

31.Z. Yu, I. Lerche, Mar. and Petr. Geology 13(2) (1996)

32. G.W. Tuckwell, L. Lonergan, R. Jolly, J. of Str. Geology 25 (2003).

33. E. Earl, J. of Agr. Eng. Res. 68 (1997)

34. E. Voznesensky, S. Nordal, Soil Dyn. and Earthquake Eng. 18 (1999)

35. J.K. Mitchell, K. Soga, Fund. of Soil Behavior (2005)

36. D.M.D. James, JGS of London 162 (2006)

37. K.J. Weber, G. Mandl, W.F. Pilaar, F. Lehner, R.G. Precious, OTC 10 (1978)

38. G. Yielding, B. Freeman, T. Needham, AAPG Bull. 81 (1997)

39. T.F. Wong, P. Baud, E. Klein, Geophys. Res. Letters 13 (2001)

40. J.W. Rudnicki, JGR 109(3) (2004).

41. B. Dehandschutter, S. Vandycke, M. Sintubin, N. Vandenberghe, L. Wouters, J. of Str. Geology 27 (2005)

42. R.A. Schultz, R. Siddharthan, Tectonophy. 411 (2005)

43. S. Reiche, B.O. Hjelstuen, H. Haflidason, Mar. Geol. 284, 1 (2011)

44. M.J. Jiang, F.G. Zhang, Y.G. Sun, Computers and Geotechnics 57 (2014)

45. L. Petracchini, M. Antonellini, A. Billi, D. Scrocca, Frontiers in Earth Science 3, 67 (2015)

46. D.Z. Oehler, N. Mangold, B. Hallet, A.G. Fairén, L. Le Deit, A.J. Williams, R.S. Sletten, J. MartínezFrías, Icarus 277 (2016)

47. D.Z. Oehler, The Plan. Rep. 8-12 (2013) 